\section{Fabrication of an Auto- clavable One-Way Valve for Venting Fermentation Gases}

BioTechniques 22:82 (January 1997)

Culturing fermentative microorganisms often requires that accumulating carbon dioxide be vented during growth. Preventing the release of such by-products usually causes inhibition of the organism, and this can then lead to a decreased yield of fermentation products such as organic acids and ethanol. It is common to release pressure with a needle placed through a septum covering the fermentation vessel. Unfortunately, this design will only keep the system anaerobic if fermentative gases are being produced rapidly enough to result in a positive displacement of air within the fermentor. Thus, the system may become aerobic as oxygen enters through the vent during the initial and late stages of the fermentation. One-way valves can be used for this purpose, but they are typically quite expensive for routine growth involving numerous culture tubes or flasks. We present a very simple and rapid method to construct an inexpensive, autoclavable one-way valve using a 1-cc syringe and a few miscellaneous items that can be found in most laboratories.

First, the plunger is removed from a 1-mL syringe (Figure 1). The rubber nub is pulled off the plunger and cut in half as shown in the diagram, with either scissors or a razor blade. The very tip portion $(2 \mathrm{a})$ is discarded, and the remaining half of the rubber nub is reinserted back into the syringe in the same orientation as before. A 4-mm glass bead creates the valve by sitting against the fabricated rubber washer in the syringe. To keep the bead snugly against the opening, a spring is inserted. Small springs may be purchased from most hardware stores, but we have found that those used in disposable pens work excellent. If desired, a small amount of glass wool can be added at this point to prevent contamination from entering through the valve. Finally, the apparatus is completed by reinserting the plunger back into the syringe until only a slight amount of pressure is against the spring. It is sealed into place by poking a needle heated with a Bunsen burner through the syringe and into the plunger at the location shown by the arrows (Figure inset). This will melt the plastic and essentially "weld" the plunger in place. The valve may be made more compact by cutting the top portion of the syringe and plunger off by using wire cutters.

Two critical points should be made regarding the construction of these valves. Occasionally, it may be necessary to fasten the fabricated rubber washer (2b) to the syringe if it does not fit tightly. We find that a couple of drops of cyanoacrylate (e.g. Superglue $^{\mathrm{TM}}$ ) will secure it to the bottom of the syringe. Also, it is important not to put too much pressure against the spring since it takes very little force to keep the glass bead seated against the rubber seal. Exceeding this will only cause extra pressure to accumulate in the fermentor before the valve is opened.

We use these valves by connecting a hypodermic needle to the end, which can then be inserted through a septum on the culture vessel. Very little oxygen was able to get into the closed system as demonstrated by using resazurin in an uninoculated tube of medium. These valves have been shown to stand up

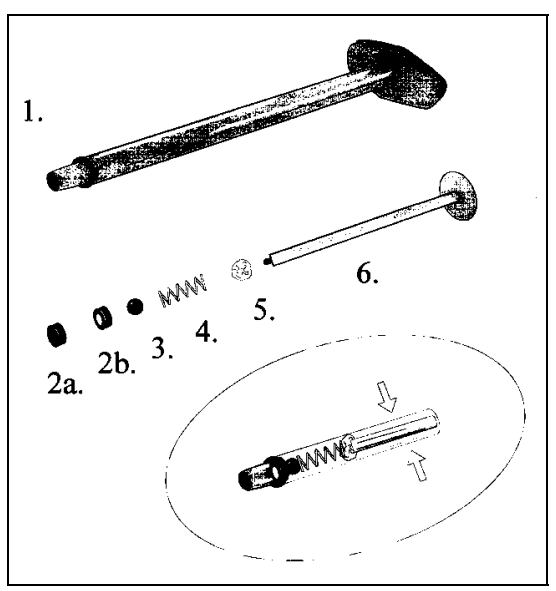

Figure 1. One-way valve constructed from a 1: 1-cc syringe; 2 , a and b: rubber nub from plunger tip cut in half; 3: 4-mm glass bead; 4: spring; 5: glass wool; 6: plunger. The inset shows a completed valve with arrows demonstrating where to use a hot needle to weld the plunger in place. well even with rapid and abundant carbon dioxide production with Saccharomyces cerevisiae in a high sugar medium. This one-way valve can also be autoclaved numerous times without any problems.

Names are necessary to report factually on available data; however, the USDA neither guarantees nor warrants the standard of the product, and the use of the name by USDA implies no approval of the product to the exclusion of others that may also be suitable. Address correspondence to Christopher D. Skory, Fermentation Biochemistry Research, National Center for Agricultural Utilization Research, USDA/ Agricultural Research Utilization, $1815 \mathrm{~N}$. University St., Peoria, IL 61604-3902, USA.

Received 28 May 1996; accepted 18 June 1996.

\section{Christopher D. Skory and Herbert A. Wyckoff USDA/Agricultural Research Utilization Peoria, IL, USA}

\section{Rapid Purification of Microtubule Motor Domain Proteins Expressed in Bacteria}

BioTechniques 22:82-85 (January 1997)

More than 75 kinesin microtubule (MT) motor proteins have been discovered since kinesin was first isolated from squid in 1985. Recently, the crystal structures of the motor domains of Drosophila kinesin heavy chain (KHC) and Ncd were reported $(3,5)$. Other than these two, none of the MT-binding motor domain proteins have been successfully purified in large enough quantity for biochemical and biophysical characterization. Here we report a rapid purification method for the Saccharomyces cerevisiae Kar3 motor domain protein, which is simpler than that 
reported previously for KHC (2), and gives a product of high purity.

The Kar3 motor domain comprises 347 amino acids and corresponds to residues 383-729 of S. cerevisiae Kar3 (4). For expression of protein, Kar3 was cloned into pMW174 and co-transformed with pACYC184/argU ${ }^{+}$(6) into competent BL31(DE3)pLysS host cells. $\arg ^{+}$is the E. coli gene for tRNA $\operatorname{Arg}_{\text {AGA }}$, which is limiting in $E$. coli. Co-transfection of $\arg U^{+}$with a gene of interest has been shown to increase bacterial expression of the gene. $S$. cerevisiae genes, which are rich in $\mathrm{A}+\mathrm{T}$, are likely to contain frequent $\operatorname{Arg}_{\text {AGA }}$ codons. The coding region of the Kar3 motor domain contains 10 $\operatorname{Arg}_{\text {AGA }}$ codons. To permit selection by tetracycline, the BamHI-HindIII fragment containing the $\arg U^{+}$gene together with its promoter was excised from the plasmid, pDC952 (6), repaired and ligated to EcoRI-digested and repaired pACYC184 to transfer the gene from the tetracycline-resistance $\left(\mathrm{Tc}^{\mathrm{R}}\right)$ into the chloramphenicol-resistance $\left(\mathrm{Cm}{ }^{\mathrm{R}}\right)$ gene of pACYC184. BL31 (DE3)pLysS cells carrying the $\mathrm{Cm}^{\mathrm{R}}$ pLysS, ampicillin-resistance $\left(\mathrm{Ap}^{\mathrm{R}}\right)$ pMW174/Kar3 and TcR pACYC184/ $\arg ^{+}$were selected by growth on 5 $\mu \mathrm{g} / \mathrm{mL}$ chloramphenicol, $50 \mu \mathrm{g} / \mathrm{mL}$ ampicillin and $5 \mu \mathrm{g} / \mathrm{mL}$ tetracycline. Colonies appeared after 2-3 days at room temperature. Kar3 protein was purified after growth with or without $\arg U^{+}$and analyzed for purity by sodium dodecyl sulfate polyacrylamide gel electrophoresis (SDS-PAGE) and electrospray ionization mass spectroscopy. The protein expressed in the presence of $\arg U^{+}$was greater in yield and appeared more homogeneous; however, there was no evidence for amino acid substitutions in protein purified after growth with or without $\arg U^{+}$, as has been shown to occur for other proteins expressed when $\arg U^{+}$, is limiting.

Bacteria cells for Kar3 expression were grown in M9ZB medium containing $5 \mu \mathrm{g} / \mathrm{mL}$ chloramphenicol, $5 \mu \mathrm{g} /$ $\mathrm{mL}$ tetracycline and $50 \mu \mathrm{g} / \mathrm{mL}$ ampicillin to optical density $\left(\mathrm{OD}_{550}\right) 0.7-$ 0.9 , and the culture flasks were rapidly cooled by swirling in ice slush. Protein expression was induced with $0.4 \mathrm{mM}$ isopropyl- $\beta$-D-thiogalactopyranoside (IPTG) at $18^{\circ} \mathrm{C}$ for $6 \mathrm{~h}$, and cells were 


\section{Benchmarks}

harvested, washed with HEM (10 mM HEPES, pH 7.2, 1 mM EGTA, 1 mM $\mathrm{MgCl}_{2}$ ), quick-frozen in liquid $\mathrm{N}_{2}$ and stored at $-80^{\circ} \mathrm{C}$. For protein purification, cells were thawed on ice in HEM at $1 \mathrm{~mL} / \mathrm{g}$ of cells, and $1 \mathrm{mM}$ phenylmethylsulfonyl fluoride (PMSF) and 1 $\mu \mathrm{L} / \mathrm{mL}$ of protease inhibitor cocktail (final concentration $=1 \mu \mathrm{g} / \mathrm{mL}$ leupeptin, $1 \mu \mathrm{g} / \mathrm{mL}$ pepstatin, $2 \mu \mathrm{g} / \mathrm{mL}$ aprotinin and $2 \mu \mathrm{g} / \mathrm{mL} \mathrm{N} \alpha$-p-tosyl-L-arginine methyl ester) were added, as described (1). After freeze-thawing, the bacterial DNA was digested by adding 100 $\mu \mathrm{g} / \mathrm{mL}$ deoxyribonuclease I, $0.5 \mathrm{mM}$ dithiothreitol (DTT), $1 \mathrm{mM} \mathrm{MgCl}_{2}, 1$ $\mathrm{mM}$ PMSF and $1 \mu \mathrm{L} / \mathrm{mL}$ protease inhibitor cocktail and incubated on ice for $30 \mathrm{~min}$. The lysate was then centrifuged at $25000 \times g(18000 \mathrm{rpm}$ in a Sorvall ${ }^{\circledR}$ SS-34 Rotor; Du Pont, Wilmington, DE, USA), and the supernatant was clarified by re-centrifugation at $100000 \times g(50000 \mathrm{rpm}$ in a Model

Table 1. Purification of Kar3 Motor Domain Protein Expressed in Bacteria

\begin{tabular}{|lccc|}
\hline & Protein (mg) & Purity (\%) & $\begin{array}{c}\text { ATPase Activity } \\
(\mu \mathrm{mol} / \mathbf{m i n} / \mathbf{m g})\end{array}$ \\
\hline Ultracentrifugation & 512 & 10 & ND \\
SP-Sepharose & 40 & 95 & 0.146 \\
Mono S & 18 & 96 & 0.148 \\
aProtein purity was estimated by scanning laser densitometry of a Coomassie \\
Blue-stained SDS polyacrylamide gel. \\
bATPase activity was measured by a pyruvate kinase/lactate dehydrogenase- \\
coupled NADH oxidation reaction in the presence of 1 MM MT (tubulin het- \\
erodimer).
\end{tabular}

TLA 100.3 Rotor; Beckman Instruments, Fullerton, CA, USA). The latter ultracentrifugation step proved to be a very effective method for removing not only insoluble bacterial proteins, but also aggregated motor protein. The resulting supernatant was applied to an SP-Sepharose ${ }^{\circledR}$ column (7-mL bed volume; Pharmacia Biotech, Piscataway,
NJ, USA) equilibrated in HEM. After extensive washing with HEM (until the protein concentration of the flowthrough was less than $10 \mu \mathrm{g} / \mathrm{mL})$, the column was eluted by stepwise increases in salt concentration in HEM. The Kar3 motor domain protein elutes at $200 \mathrm{mM} \mathrm{NaCl}$. The purity of the peak eluate fraction is approximately $90 \%$ 


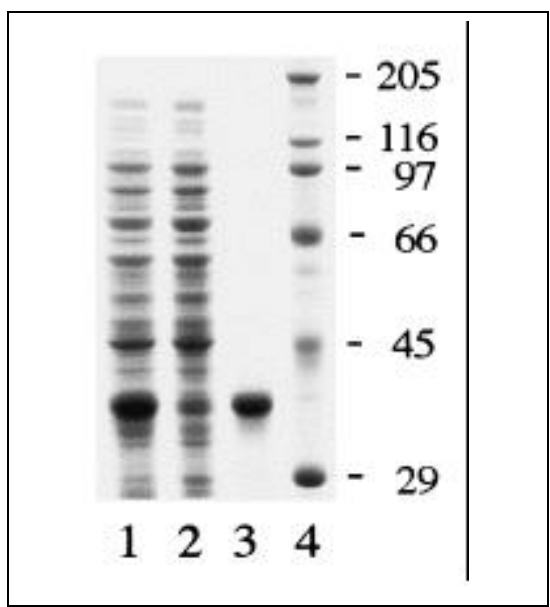

Figure 1. SDS-PAGE of S. cerevisiae Kar3 motor domain purification. Protein from various stages of purification was applied to a 10\% SDS polyacrylamide gel and stained with Coomassie ${ }^{\circledR}$ Blue following electrophoresis. Chromatography on Mono S or Superose 12 removed minor bands of contaminants; the protein profiles were almost the same as that shown for SP-Sepharose. Lane1, supernatant after ultracentrifugation $(20 \mu \mathrm{g})$; lane 2 , flow-through fraction of SP-Sepharose (20 $\mu \mathrm{g})$; lane 3, peak eluate fraction of SP-Sepharose $(3 \mu \mathrm{g})$; and lane 4 , molecular mass markers in kilodaltons.

95\% as judged by scanning laser densitometry following SDS-PAGE (Figure 1).

For further purification, the peak fractions were combined, diluted twofold with HEM and purified by Mono $\mathrm{S}^{\circledR}$ (Pharmacia Biotech), followed by Superose $^{\circledR} 12$ fast protein liquid chromatography (FPLC) (Pharmacia Biotech). The Mono S chromatograph showed two peaks upon elution of the column with a linear gradient of 0-500 $\mathrm{mM} \mathrm{NaCl}$, a major peak at $200 \mathrm{mM}$ $\mathrm{NaCl}$ and a smaller peak at $230 \mathrm{mM}$ $\mathrm{NaCl}$. Both peaks consisted of highly purified Kar3 motor domain protein by SDS-PAGE, and the ATPase-specific activity in the presence of $1 \mu \mathrm{M}$ MT of protein from both peaks was nearly the same. The level of purity of the major peak, which comprised approximately $80 \%$ of the protein, is adequate for many biochemical applications, including crystallization trials. Minor contaminants present in the major peak could be removed by chromatography on Superose 12. The major peak from Mono S or the peak from Superose 12 was used for biochemical experiments. The purity of either peak was approximately $96 \%$. The purification proce- dure through Mono S can be easily completed in one day, therefore the purified protein does not require storage on ice for a prolonged time (overnight) nor subjection to repeated freeze/thawing, which could contribute to protein denaturation before use. Protein purity, as evaluated by SDS-PAGE, is illustrated in Figure 1, and the purification is summarized in Table 1. These methods are applicable to other bacterially expressed motor proteins as well as other types of bacterially expressed proteins.

\section{REFERENCES}

1.Chandra, R. and S.A. Endow. 1993. Expression of microtubule motor proteins in bacteria for characterization in in vitro motility assays. Methods Cell Biol. 39:115-127.

2.Gilbert, S.P. and K.A. Johnson. 1993. Expression, purification, and characterization of the Drosophila kinesin motor domain produced in Escherichia coli. Biochemistry 32:4677-4684.

3.Kull, F.J., E.P. Sablin, R. Lau, R.J. Fletterick and R.D.Vale. 1996. Crystal structure of the kinesin motor domain reveals a structural similarity to myosin. Nature (London) 380:550-555.

4.Meluh, P.B. and M.D. Rose. 1990. Kar3, a kinesin-related gene required for yeast nuclear fusion. Cell 60:1029-1041.

5.Sablin, E.P., F.J. Kull, R. Cooke, R.D. Vale and RJ. Fletterick. 1996. Crystal structure of the motor domain of the kinesin-related motor ncd. Nature (London) 380:555-559.

6.Spanjaard, R.A., K. Chen, J.R. Walker and J. van Duin. 1990. Frameshift suppression at tandem AGA and AGG codons by cloned tRNA genes: assigning a codon to $\arg U$ tRNA and T4 tRNAArg. Nucleic Acids Res. 18:5031-5036.

This work was supported by grants to S.A.E. (National Institutes of Health GM46225 and American Cancer Society $C B-47)$. Address correspondence to Sharyn A. Endow, Department of Microbiology, Duke University Medical Center, Durham, NC 27710, USA. Internet: endow@ galactose.mc.duke.edu

Received 8 May 1996; accepted 18 June 1996.

Hebok Song and Sharyn A. Endow

Duke University Medical Center Durham, NC, USA 